\title{
QUASI-STATIC THERMAL MODELLING OF MULTI-SCALE SLIDING CONTACT FOR UNLUBRICATED BRUSH SEAL MATERIALS
}

\author{
Qingfeng Xia \\ Osney Thermofluids Laboratory, \\ University of Oxford, \\ Parks Road, Oxford, OX1 3PJ, UK \\ qingfeng.xia@eng.ox.ac.uk

\section{Andrew Owen} \\ Osney Thermofluids Laboratory, \\ University of Oxford, \\ Parks Road, Oxford, OX1 3PJ, UK \\ Andrew.Owen@eng.ox.ac.uk
}

\author{
*David Gillespie \\ Osney Thermofluids Laboratory, \\ University of Oxford, \\ Parks Road, Oxford, OX1 3PJ, UK \\ David.Gillespie@eng.ox.ac.uk \\ Gervas Franceschini \\ Transmissions, Structures and Drives, \\ Rolls-Royce plc, \\ Moor Lane, Derby, DE24 8BJ, UK \\ Gervas.Franceschini@Rolls-Royce.com
}

\begin{abstract}
Prediction of contact temperature between two materials in high speed rubbing contact is essential to model wear during unlubricated contact. Conventionally assumptions of either steady or an annular heat sources are used for slow and high speed rotation respectively. In this paper, a rotating heating source is solved using an in-house finite element method code. This captures the full geometry and rotating speed of the rubbing bodies. Transient heat transfer is modelled quasi-statically, eliminating the need for a transient $3 D$ simulation. This model is shown to be suitable for contact temperature prediction over a wide range of rotating speeds, anisotropic thermal conductivity, and non-uniform thermal boundary conditions. The model calculates heat partition accurately for a thin rotating disc and short pin combination, which cannot be predicted using existing analytical solutions. The method is validated against ANSYS Mechanical and experimental infra-red thermography. Results demonstrate that the annular source assumption significantly under-predicts contact temperature, especially at the rubbing interface. Explicit modelling of a thin disc results higher heat partition coefficients compared with the commonplace semiinfinite length assumption on both static and rotating components. The thermal anisotropy of tuft-on-disc configurations is evaluated and compared to a uniform pin-ondisc configuration. Despite the effective thermal conductivity in the bristle tuft being approximately one order of magnitude lower than along the bristle length (treating the bristle pack as a porous medium), its impact on heat partition and contact temperature is shown to be limited.
\end{abstract}

\section{INTRODUCTION}

Leakage past seals have long been known to decrease engine efficiency: these may typically be responsible for a $4 \%-6 \%$ drop in power as well as an increase of the specific fuel consumption of $3 \%-5 \%$ [1]. Advanced sealing concepts have been attempted such as actively controlled gap seal, brush seal, leaf seal and finger seal, to replace the labyrinth seals for a significant reduction in air flow leakages. Among these approaches, brush sealing is advantageous over labyrinth seals for compliance to accommodate transient shaft excursions [2], and it has been widely adopted in military aero-engines. Further introduction of brush seals into higher duty and higher life applications has been more difficult due to wear and deterioration giving limited service life. Therefore, a better understanding of wear mechanisms at high temperature and high sliding speeds are fundamentally important for brush seal designers to extend the service time.

The extreme working environment of the brush seal, high sliding speed and temperature, is the major obstacle for the experimental study of seal tribology in laboratory. Brush seals are designed to work at speeds up to $450 \mathrm{~m} \mathrm{~s}^{-1}$ [1] and tip loads up to $70 \mathrm{kPa}$ [3] in ambient temperatures up to $800{ }^{\circ} \mathrm{C}$. Most of the previous work reported on tribological evaluation of brush seals $[3,4]$ has been done at high temperature at lower sliding speeds or high sliding speeds at the room temperature. For the high speed wear test of brush seals [5], the conventional pin-ondisc configuration has been adopted, replacing solid pin with a tuft, i.e. a sealing filaments bundle. To mimic the engine seal working condition, the tuft is oriented to the rotor surface with a lay angle (typically around $45^{\circ}$ ) pointing in the direction of rotation.

Precise prediction of the tuft and rotor contact temperature is crucial for designing engine seal. The oxidation and wear process heavily depends on contact temperature. At high sliding speeds, friction heating determines the temperature rise at the high spots of the contacting surface, instead of the ambient temperature. The temperature at local asperities of the bristle tip could be elevated to a value comparable with realistic engine temperature, and the matching of contact temperature in laboratory wear test with that in engine environment can improve the modelling fidelity for seal service time estimation. 
Furthermore, wear mechanisms and formation of tribo-films depend significantly on the contact temperature and hence oxidation characteristics of the sliding surfaces [5].

The temperature measurement for a sliding interface is challenging for the high sliding speeds and high thermal gradients, while a hybrid approach of numerical modelling with experimental validation is promising. The contact temperature cannot be measured directly by thermal photography, while a thermocouple embedded into the tuft is subjected to wear at the interface. Recently, a precise measurement of the friction coefficient at high sliding speeds can be used to calculate the frictional heating for the given contacting force and sliding speed. Taking into account the non-uniform convective heat transfer coefficient for the high speed rotating disc and the distinct characteristics of a bristle tuft, a quasi-static FEM model can predict the thermal distribution of the static tuft and rotating disc, without the cost of transient heat conjugate heat transfer simulation. Therefore, the average contact temperature and heat partition can be predicted by numerical simulation.

Furthermore, the anisotropy of the thermal conductivity should be considered for the thermal analysis of the tuft-on-disc configuration. For the typical hexagonal bristle packing, a reduced heat conductivity on tuft cross-section compared to the bulk bristle material is anticipated. Different from engine brush seals with cross flow, natural or forced heat convection between bristles, heat transfer within the bristle gap is not significant for the bristle diameters of less than $1 \mathrm{~mm}$. Because air has a very small thermal conductivity compared with metal material and the contact width between bristles, the heat conduction in the radial direction is much smaller than that along the bristle length direction. The large quantity of bristles in a tuft sample can be modelled as an anisotropic porous medium, whose effective thermal conductivity (ETC) can be investigated numerically [6].

In this paper, quasi-static thermal distributions for the pinon-disc and tuft-on-disc configurations are solved by an in-house FEM solver, without the computational cost of 3D transient simulation. The advantages of this quasi-model over the existing solutions based on static heat source or geometrical simplifications are demonstrated, and heat partition is directly calculated from a thin volumetric heat source layer at the rubbing contact. Furthermore, anisotropy of heat transfer conduction in tuft is numerically evaluated and the effective thermal conductivity is modelled against the inter-bristle indentation or gap.

\section{ANALYTICAL MODELLING}

\subsection{Governing equations for transient heat transfer}

The conventional pin-on-disc tribology configuration is illustrated in Fig. 1, where $\boldsymbol{r}, \boldsymbol{z}$ and $\boldsymbol{\theta}$ are the cylindrical coordinates; $\boldsymbol{\omega}$ is the rotating speed $(\mathrm{rad} / \mathrm{s}) ; \boldsymbol{r}_{\boldsymbol{d}}$ and $\boldsymbol{r}_{\boldsymbol{p}}$ are the outer radius for the disc and pin respectively. Two distinct cylindrical coordinate systems are defined for the disc and the pin, while the contacting surface is shared as the $\mathrm{z}$-plane, $z=0$. The pin centre is located at $\boldsymbol{\theta}=0$ on the disc coordinate system with an eccentricity of $\boldsymbol{e}$

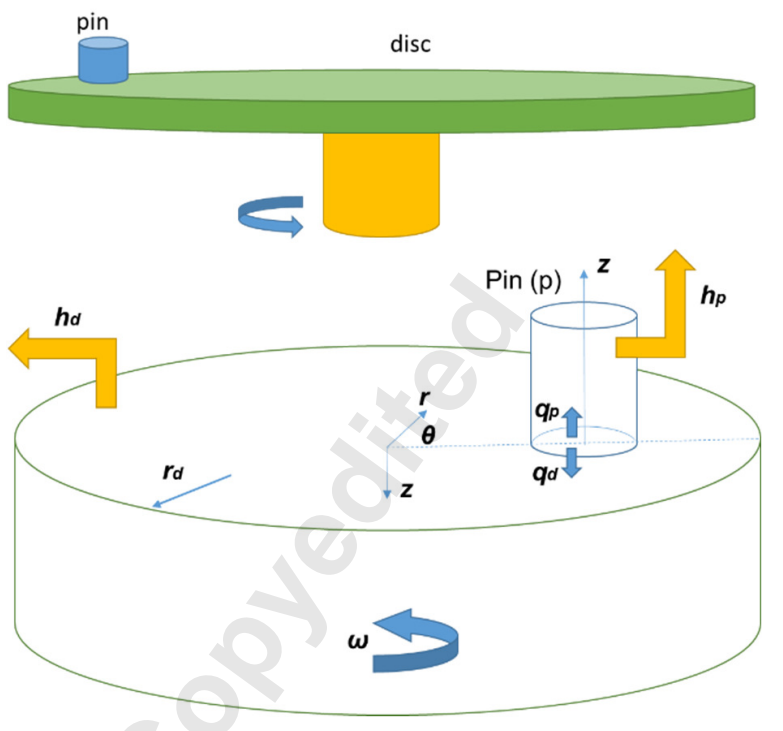

Fig. 1 Schematic of pin-on-disc configuration for high speed tribology test

The governing equation for transient heat transfer in cylindrical coordinate system is denoted as:

$$
\frac{1}{r} \frac{\partial}{\partial r}\left(r \frac{\partial T_{\mathrm{d}}}{\partial r}\right)+\frac{1}{r^{2}} \frac{\partial^{2} T_{\mathrm{d}}}{\partial \theta^{2}}+\frac{\partial^{2} T_{\mathrm{d}}}{\partial z^{2}}-\frac{\partial T_{\mathrm{d}}}{\alpha_{\mathrm{d}} \partial t}=0
$$

The boundary conditions for a disc treated as a semi-infinite cylinder are defined as:

$$
\begin{aligned}
& \left(\frac{\partial T_{\mathrm{d}}}{\partial r}\right)_{r=0}=0, \quad\left(\frac{\partial T_{\mathrm{d}}}{\partial r}\right)_{r=r_{d}}=0 \\
& -k_{\mathrm{d}}\left(\frac{\partial T_{\mathrm{d}}}{\partial z}\right)_{z=0}=\left\{\begin{array}{cc}
q_{\mathrm{d}} & \text { (in contact) } \\
-h_{\mathrm{d}} T_{\mathrm{d}} & \text { (elsewhere) }
\end{array},\left(T_{\mathrm{d}}\right)_{z \rightarrow \infty}=0\right.
\end{aligned}
$$

where $h_{\mathrm{d}}$ is the convective heat transfer coefficient (HTC) based on the ambient temperature; $q_{\mathrm{d}}$ is the heat flux into the disc; $T_{\mathrm{d}}$ is the temperature distribution on the disc; $\lambda_{\mathrm{d}}$ and $\alpha_{\mathrm{d}}$ are the thermal conductivity and diffusivity for the disc material.

For the thermal distribution on the pin, an analytical solution is achievable if homogenous thermal distribution is assumed in the radial and angular positions.

$$
\mathrm{Bi}_{\mathrm{p}}=\frac{r_{p} h_{\mathrm{p}}}{k_{p}}
$$

where $\boldsymbol{h}_{\boldsymbol{p}}$ is the constant convective heat transfer coefficient; $\alpha_{\mathrm{p}}$ is diffusivity. Thereby, the governing equation and boundary conditions for thermal distribution on the semi-infinite cylinder is given as,

$$
\begin{aligned}
& \frac{\mathrm{d}^{2} T_{\mathrm{p}}}{\mathrm{d} z^{2}}-\frac{2 h_{\mathrm{p}}}{\lambda_{\mathrm{p}} r_{p}} T_{\mathrm{p}}=0 \\
& -\lambda_{\mathrm{p}}\left(\frac{\mathrm{d} T_{\mathrm{p}}}{\mathrm{d} z}\right)_{z=0}=q_{\mathrm{p}}, \quad\left(T_{\mathrm{p}}\right)_{z \rightarrow \infty}=0
\end{aligned}
$$


where $\boldsymbol{q}_{\boldsymbol{p}}$ is the heat flux into the pin; $\boldsymbol{T}_{\boldsymbol{p}}$ is the temperature distribution on the pin; $\lambda_{p}$ is the thermal conductivity for the pin material.

The solution for the simplified pin model in Eq. (5) can be solved by integral transform [7]:

$$
T_{\mathrm{p}}(z)=\frac{q_{\mathrm{p}} r_{p}}{\lambda_{\mathrm{p}}} \frac{1}{\sqrt{2}} \sqrt{\frac{\lambda_{\mathrm{p}}}{h_{\mathrm{p}} r_{p}}} e^{-z \sqrt{2 h_{\mathrm{p}} / \lambda_{\mathrm{p}} r_{p}}}
$$

Although an analytical solution of the pin-on-disc [7] can predict the thermal distribution on the disc without solving the transient 3D heat transfer problem, it is not precise for a thin disc with high rotating speeds. The analytical solution is based on several assumptions: the disc is regarded infinite in the thickness direction; the ambient temperature is set as zero; a constant convective heat transfer coefficient on the surface is adopted; at the disc $\operatorname{rim} \boldsymbol{r}=\boldsymbol{r}_{\boldsymbol{d}}$, a zero gradient instead of the convective heat transfer boundary is used.

On the other hand, an FEM analysis is preferred for a rotating disc with finite thickness for high speed tribology tests. Conventionally, an assumption of either a steady heat flux at the contact area for slow rotating speeds or an annular source at high speeds is necessary to treat the pin-on-disc as static heat transfer problem. The convective heat transfer boundary conditions will be adopted for all the surfaces of the rotating disc; the local heat transfer coefficient on the disc surface is a function of rotating speed and radial position, instead of constant heat transfer coefficient in the low speed pin-on-disc test. The frictional heating at the pin-on-disc interface can be analogised into the annular heat source in the steady heat transfer problem, if the disc rotating speed is sufficiently high. The annular heat source instead of the moving heat source is applicable, if Peclet number $>1$. Peclet number is defined from heat source speed $\boldsymbol{V}_{\boldsymbol{p}}$ and length scale $\boldsymbol{r}_{\boldsymbol{p}}$ :

$$
\mathrm{Pe}=V_{p} r_{p} / \alpha_{\mathrm{d}}
$$

Furthermore, a quasi-static analysis can improve the thermal modelling fidelity for the sliding interface. The interface area is different from the other part the sliding track for the absence of convective cooling. The interface area might have the highest temperature for the frictional heating generation. Relative to the pin's coordinate system, the thermal distribution on the rotating disc is quasi-static, if the pin-on-disc system reaches the equilibrium state. The governing equation for heat transfer in Eq. (1) is transformed into the quasi-static form with the boundary conditions.

$$
\begin{aligned}
& \frac{1}{r} \frac{\partial}{\partial r}\left(r \frac{\partial T_{\mathrm{d}}}{\partial r}\right)+\frac{1}{r^{2}} \frac{\partial^{2} T_{\mathrm{d}}}{\partial \theta^{2}}+\frac{\partial^{2} T_{\mathrm{d}}}{\partial z^{2}}-\frac{\omega}{\alpha_{\mathrm{d}}} \frac{\partial T_{\mathrm{d}}}{\partial \theta}=0 \\
& \left(T_{\mathrm{d}}\right)_{\theta=-\pi}=\left(T_{\mathrm{d}}\right)_{\theta=\pi}, \quad\left(\frac{\partial T_{\mathrm{d}}}{\partial \theta}\right)_{\theta=-\pi}=\left(\frac{\partial T_{\mathrm{d}}}{\partial \theta}\right)_{\theta=\pi}
\end{aligned}
$$

\subsection{Heat transfer coefficient for rotating disc}

The convective heat transfer on a rotating disc has been widely studied, and empirical equations are available without the cost of transient conjugate heat transfer for laminar, transitional and turbulent flows on a rotating disc [8]. The local convective heat transfer performance is modelled as the local Nusselt number $\mathbf{N u} \mathbf{u}_{\mathbf{r}}$, as a function of the local Reynolds number $\mathbf{R e}_{\mathbf{r}}$ and the radial position $\boldsymbol{r}$.

$$
\begin{aligned}
& \mathrm{Nu}_{\mathrm{r}}=a \mathrm{Re}_{\mathrm{r}}^{\mathrm{b}} \\
& \mathrm{Re}_{\mathrm{r}}=\omega r^{2} / v
\end{aligned}
$$

where $\mathbf{a}$ and $\mathbf{b}$ are empirical constants fitting from numerical and experimental results; $v$ is the kinetic viscosity of the ambient fluid outside the boundary layer, which is air in the current study. Thence, the local heat transfer coefficient is derived.

$$
h_{d}(r)=\frac{\alpha_{\mathrm{f}} \mathrm{Nu}_{\mathrm{r}}}{r}=\frac{q}{T_{\text {wall }}-T_{\text {adiabatic }}}
$$

where $\alpha_{\mathrm{f}}$ is the thermal conductivity of the ambient fluid. Note that this definition uses the wall adiabatic temperature instead of the ambient temperature of the entrained flow, Eq. (1).

Depending on Reynolds number, $\mathbf{a}$ and $\mathbf{b}$ take different values [9]. For laminar flow, these are independent of Reynolds number. Also required is the exponent $\mathbf{n}$, assuming a temperature distribution on the disc, $T=T_{0} r^{\mathrm{n}}$. This equals zero for an isothermal boundary condition on the disc.

$$
\mathbf{a}=\frac{0.4435}{0.3486+2.002 /(2+\mathbf{n})}, \mathbf{b}=0.5
$$

In the transient flow regime, several empirical correlations may are applicable based on Reynolds number; e.g. [10]:

$$
\begin{aligned}
\mathbf{a}=2.65 \times 10^{-20}, \mathbf{b} & =4 \\
& \text { for } 2.9 \times 10^{5}<\operatorname{Re}_{\mathrm{r}}<3.6 \times 10^{5}
\end{aligned}
$$

Once there is full transition to turbulent flow (above $\mathbf{R e}_{\mathbf{r}}=1.8 \times$ $\left.10^{5}[11]\right)$,

$$
\mathbf{a}=\frac{1}{34.99+48.33 /(2.6+n)}, \mathbf{b}=0.8
$$

For a cylinder in a cross flow, the heat convective coefficient on the cylinder surface is not homogenous but a function of angular position. However the averaged heat transfer coefficient can be used without significant impact on the heat partition or temperature distribution within the pin providing the Biot number for the pin is low $(\mathbf{B i}<0.1)$. The Zukauskas correlation [12] for average Nusselt number based on the far field temperature was used:

$$
\overline{N u_{D}}=\operatorname{CRe}_{\mathrm{D}}{ }^{m} \operatorname{Pr}_{\mathrm{s}}{ }^{n}\left(\frac{\operatorname{Pr}}{\operatorname{Pr}_{\mathrm{s}}}\right)^{1 / 4}
$$

where $\operatorname{Re}_{\mathrm{D}}$ is the Reynolds number based on the cylinder diameter; Pr is Prandtl number which is 0.72 for air; $\operatorname{Pr}_{\mathrm{s}}$ is Prandtl number based on film temperature (the average of the surface and ambient temperatures). For $\operatorname{Pr}<10, \boldsymbol{n}=0.37$; for $\operatorname{Re}_{\mathrm{D}}$ in range of 1000 200000, $\mathbf{C}=0.26$ and $\boldsymbol{m}=0.6$.

For the specific case of the pin on rotating disc, the cross flow is not uniform in the pin's axial direction. The cross-flow velocity drops quickly with the distance to the rotating surface. Without the blockage of the pin, the boundary layer thickness $\delta$ on the disc is estimated by viscosity $v$ and rotating speed $\omega[13]$. 


$$
\delta=5.5 \sqrt{\frac{v}{\omega}}
$$

\subsection{Flash temperature rise}

Assuming a uniform contact pressure on the sliding interface, the average contact temperature can be predicted by a uniform heating rate $\boldsymbol{Q}$ [14]. For large values of $P e(>10)$, the average temperature at the contacting area is given by,

$$
\bar{T} \approx \frac{4 Q}{3 \pi^{1 / 2}} \mathrm{Pe}^{-1 / 2}
$$

However, heat generation is not homogenous due to imperfect contact condition due to local asperities. The maximum temperature, $T_{\max }$, surpasses the spatially-averaged temperature, which is also denoted as bulk temperature, $T_{\text {bulk }}$. The extra portion above the bulk temperature is denoted as the flash temperature rise, $T_{\text {flash }}$, and it is usually significantly higher than the bulk temperature with a very short duration.

The maximum contact temperature can accelerate thermally activated processes, such as oxidation and phase transformations, and thus the maximum temperatures are potentially much more important than the bulk temperature in surface deterioration. For example, recrystallization is found for a Haynes 25 tuft sliding against a Nitrided disc [5], suggesting the maximum contact temperature reaches $1100^{\circ} \mathrm{C}$.

\subsection{Partition of heat}

Frictional heating is generated at the sliding interface; the total heat flux generated, $\boldsymbol{q}_{g}$, is partitioned into the disc and pin, denoted as $\boldsymbol{q}_{\boldsymbol{d}}$ and $\boldsymbol{q}_{\boldsymbol{p}}$ respectively.

$$
q_{g}=q_{d}+q_{p}
$$

In order to determine how the generated heat is partitioned between the pin and disc, an assumption of the thermal distribution on the sliding interface is necessary. Blok presumes the perfect contact between the pin and disc and postulates heat flux conservation (equal maximum temperature) at the interface.

$$
T_{\mathrm{d}, \mathrm{avg}}=T_{\mathrm{p}, \mathrm{avg}}, T_{\mathrm{d}, \mathrm{avg}}=q_{d} R_{d}, T_{\mathrm{p}, \mathrm{avg}}=q_{p} R_{p}
$$

where $\boldsymbol{R}_{\boldsymbol{d}}$ and $\boldsymbol{R}_{\boldsymbol{p}}$ are the thermal resistances for of the disc contact area and the pin contact area respectively; $T_{\mathrm{p}, \text { avg }}$ and $T_{\mathrm{p} \text {,avg }}$ are the average temperature of the disc contact area and the pin contact area respectively.

The thermal resistance from the interface to the pin $R_{d}$ is deduced by a series integration from [7]. It is written as,

$$
R_{\mathrm{d}}=\frac{r_{p}^{2}}{h_{\mathrm{d}} r_{d}^{2}}+4 \sum_{m=0}^{\infty} \sum_{n=1}^{\infty} \frac{\varepsilon_{m} J_{1}^{2}\left(\beta_{n} r_{p}\right) J_{m}^{2}\left(\beta_{n} e\right) \cos (\psi)}{\left[\left(\beta_{n} r_{d}\right)^{2}-m^{2}\right] J_{m}^{2}\left(\beta_{n} r_{d}\right) \delta}
$$

where $\boldsymbol{m}$ and $\boldsymbol{n}$ are integers; $J$ is Bessel function of the first kind; $\varepsilon, \delta, \beta$ and $\psi$ are variables defined in the integral transform in the reference [7]. On the other hand, the thermal resistance from the tribo-interface into the pin has the form:

$$
R_{\mathrm{p}}=\frac{r_{p}}{\lambda_{\mathrm{p}} \sqrt{2}} \sqrt{\frac{\lambda_{\mathrm{p}}}{h_{\mathrm{p}} r_{p}}}
$$

Thereby, we can obtain the percentage of heat flux generated by friction that is evacuated by the disc. This percentage is called the heat partition coefficient, which is denoted as $p_{\mathrm{d}}$,

$$
p_{\mathrm{d}}=\frac{q_{d}}{q_{g}}=\frac{R_{p}}{R_{d}+R_{p}}
$$

Another solution for the heat partition at Peclet numbers $>10$ given by Archard [15] suggests,

$$
p_{\mathrm{d}}=\frac{0.785 \lambda_{\mathrm{d}} \sqrt{\mathrm{Pe}}}{0.785 \lambda_{\mathrm{d}} \sqrt{\mathrm{Pe}}+0.974 \lambda_{\mathrm{p}}}
$$

Tian and Kennedy brought up a similar equation for heat partition [14]. Notably, constant HTC and semi-infinite cylinder are assumed for the pin and the disc in Eq. (18-23), which may lead to a significant error in heat partition if thin discs and short pins are utilised. Other solutions of partitioning are based on functional analysis and iterative methods.

\subsection{Anisotropy of heat conductivity of bristle tuft}

The thermal distribution for the tuft-on-disc is distinct from that of a solid pin in the conventional pin-on-disc configuration for the anisotropic heat conduction within the bristle bundle. Fig. 2 shows a schematic of the brush seal tuft used in this test programme. The tuft, comprising a bundle of a fixed number of individual bristles, has the same function as the pin in a conventional pin-on-disc type tribology setup. Bristles in the tuft are tilted at an angle relative to the sliding motion direction on the disc, and this angle is consistent with the lay angle of brush seal elements for a typical brush seal.

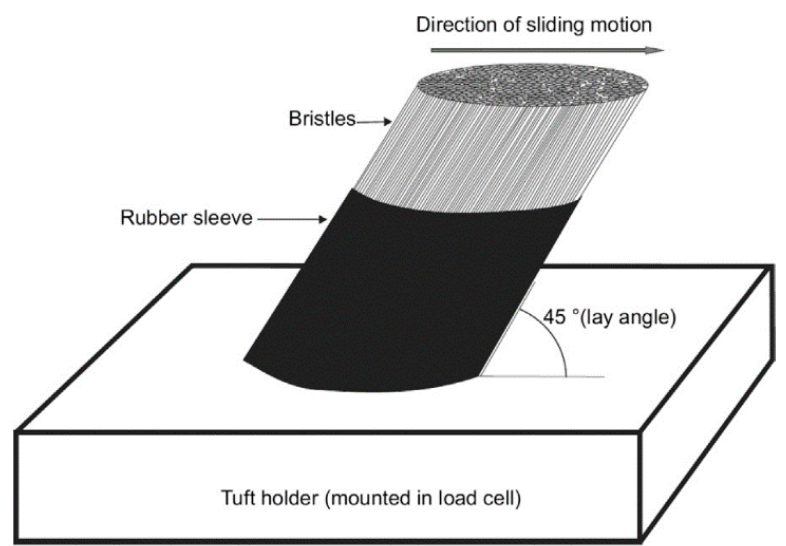

Fig. 2 Bristle tuft with 45 degree lay angle for tribology test [5]

This tuft-and-disc setup can simulate contact conditions of a static brush seal and a rotating shaft and can be analysed comparatively with the traditional pin-on-disc method. A tightly packed bundle is ensured through the use of a shrink fit plastic outer sleeve or a copper sleeve which is used to constrain the bristles within a cylindrical volume and thus bristle bundle can 
be clamped into a metal holder using grub screws. Rigidity due to the close packing of multiple bristles in the tuft allows the contact pressure applied at bristle tips to be accurately measured by mounting the tuft in a load cell. The contact pressure is assumed to be equal on all bristles.

The bristle in tuft is made of Haynes 25, a high temperature superalloy. Haynes 25 has excellent mechanical properties below $650{ }^{\circ} \mathrm{C}$. In this numerical study, the thermal properties near the room temperature range are adopted from Table 1.

Table 1 Thermal property of for a typical brush filament material

\begin{tabular}{|l|l|l|l|}
\hline $\begin{array}{l}\text { Material } \\
\text { properties }\end{array}$ & Quantity & U.S. unit & Temperature \\
\hline Density & $9130\left(\mathrm{~kg} \mathrm{~m}^{-3}\right)$ & & $20-100{ }^{\circ} \mathrm{C}$ \\
\hline $\begin{array}{l}\text { Thermal } \\
\text { conductivity }\end{array}$ & $10\left(\mathrm{~W} \mathrm{~m}^{-1} \mathrm{~K}^{-1}\right)$ & & at $20^{\circ} \mathrm{C}$ \\
\hline $\begin{array}{l}\text { Mean thermal } \\
\text { expansion } \\
\text { coefficient }\end{array}$ & $12.9 \times 10^{-6}\left(\mathrm{~K}^{-1}\right)$ & & $21-204^{\circ} \mathrm{C}$ \\
\hline Specific Heat & $400\left(\mathrm{~J} \mathrm{~kg}^{-1} \mathrm{~K}^{-1}\right)$ & & $28-100{ }^{\circ} \mathrm{C}$ \\
\hline
\end{tabular}

High conductivity is expected along the length of the bristle but should be lower in the radial direction through the entire tuft because of voids and contact resistance. Macroscopic natural convection within gaps is not likely due to the low thermal gradients, and the very high aspect ratio of these volumes. Conductivity ratios between the bristle tuft and solid pin can be defined along the cylindrical axis of pin and perpendicular to it. Along the axis this ratio is approximately the filling factor of the bristle bundle, assuming negligible contribution from the air. For perfect hexagonal packing of circular bristles the filling factor is 0.907 .

$$
\frac{\mathrm{ETC}}{k_{\text {metal }}}=\text { filling factor }
$$

The effective heat conductivity normal to the cylindrical axis $-\mathrm{a}$ pseudo-radial direction - is a combination of heat conduction through bristle contact, radiative, convective and conductive heat transfer within the gaps.

$$
\mathrm{ETC}=k_{s}+k_{g}
$$

where $k_{s}$ and $k_{g}$ are contributions from solid contact, and heat transfer within the air gaps respectively.

The contribution from bristle contact, modelled here by material fusion, is highly sensitive to extent of the contact area. The contact length scale between bristles is small compared with the bristle diameter, according to Hertzian contacting theory. For contact between two cylinders with parallel axes, the indentation depth, $d$, is represented as:

$$
d=\frac{4 F}{\pi \mathrm{E}^{*} R^{*}}
$$

where $\boldsymbol{F}$ is the contacting force; $\boldsymbol{R}^{*}$ is the equivalent radius of the parallel cylinders. Assuming identical material for the two cylinders of the same radius $\mathbf{r}, \boldsymbol{R}^{*}$ and $\boldsymbol{E}^{*}$ is calculated.

$$
\frac{1}{E^{*}}=2 \frac{1-v^{2}}{E}, \frac{1}{R^{*}}=\frac{1}{\mathrm{r}}+\frac{1}{\mathrm{r}}
$$

where $v$ is material Poisson ratio.

Smooth cylinder contact leads to perfect material contact without a gap, resulting in no contact thermal resistance. In realistic situations, contact between bristles is not continuous along the bristle lengths due to the non-uniform bristle diameters and imperfect circular cross-sections. The real contacting pressure is significantly higher than the nominal pressure $p_{\text {nominal }}$ at local asperities. The roughness of the surface in contact may have an impact on the effective thermal conductivity. Thermal contact resistance, $R_{c}$, can be predicted by [16],

$$
1 / R_{c}=1.25 \frac{k^{*} A_{\text {nominal }} m^{*}}{\sigma^{*}}\left(\frac{p_{\text {nominal }}}{H}\right)^{0.95}
$$

where $H$ is micro-hardness; $k^{*}$ is the effective contact conductivity which is equal to that of bulk metal. For two rough surfaces in contact, the effective roughness height and the slope of the asperities are defined as,

$$
\sigma^{*}=\sqrt{\sigma^{1}+\sigma^{2}} \text { and } m^{*}=\sqrt{m^{1}+m^{2}}
$$

where $m=\frac{1}{L} \int_{0}^{L}\left|\frac{d y}{d x}\right| d x$ is the surface slope along the length scale $L$ and $\sigma$ is the surface roughness height. In this numerical study, the contact width is only a few micrometres, and the real contact pressure is highly comparable to the micro-hardness. Since a typical radius of micro-contact spot approximates to 5$10 \mu \mathrm{m}$ [16] for macro-scale rough surface thermal resistance modelling, asperity plastic micro-contact can be treated as if it were material fusion. In addition, air molecules' ballistic collisions can substantially enhance heat transfer between surfaces with nano-scale separation. This is the not classical density driven natural convection but rather as a result of Brownian motion between nearby solid surfaces. This ballistic heat transfer mechanism is only dominant in the molecular flow regime. Therefore, the contact resistance is neglected at the micro-contact regions in this simulation.

For the contacting bristles in a tuft, a filling ratio can be calculated from the integral of the tuft mesh cells in the numerical model. A further characteristic ratio is that of the total contacting width $\boldsymbol{w}$ to the perimeter for each bristle.

$$
\mathrm{R}_{c p}=\frac{N w}{2 \pi \mathrm{r}}
$$

where $N$ is the number of contacting bristles around each bristle.

Heat transfer within the air gap between bristle at microscale is complicated. However, for the atmospheric pressure and room temperature ambient conditions experienced in tribology tests, radiative effects are considered negligible. In the absence of large pressure differences across the bristles, the inter-bristle air velocity can be similarly considered to be zero. Thermal diffusion is, therefore, the major mechanism for heat conduction within the gaps. Here the hydraulic diameter of the gap is in the order of tens of microns, much larger than the free path of air at atmospheric pressure. The appropriateness of the use of Fourier heat conduction in a fluid continuum consumption is now determined using the Knudsen number:

$$
\mathrm{Kn}=\lambda / L
$$


where $\lambda$ is the free path of air and $L$ is the length scale of the gaps. The Knudsen number range in this study is less than 0.06, which remains in the regime of slip-flow or continuum flow.

Mimicking macroscale natural convection, Nusselt number is defined as.

$$
\mathrm{Nu}=h L / k_{\text {air }}
$$

where the length scale $L$ is the distance between the hot and cold surface chosen as the hydraulic diameter of the air gap; $h$ is the macro-scale convective heat coefficient.

The thermal conductivity for the gap region can be modelled as [17],

$$
k_{\mathrm{g}}=1 /(1+f) k_{\mathrm{air}}(1+\mathrm{Nu})
$$

where $f$ is a correction factor which can be taken as Knudsen number in the slip and transition flow regimes [18]. Nusselt number due to macroscale natural convection is small as 0.1[17], due to the small length scale of the air gap. For the small $\mathrm{Kn}$ in the current test conditions, $k_{\mathrm{g}}$ is approximately the air thermal conductivity.

\section{EXPERIMENTAL MEASUREMENT SETUP}

The high-speed tuft-on-disc tribology rig comprises a rotating disc driven by an air motor and the brush seal tuft mounted on the top of a cantilever type load cell pressing against this rotating disc as shown in Figure 3. The load cell with metal foil resistive strain sensor measures the contacting force at the tribo-interface; the contacting force is controllable as the load cell is driven against the rotating disc along a linear guide by a DC motor. A torque meter (surface acoustic wave strain sensing type) sits between the air motor and the rotating disc, and measures the torque. From these the coefficient of friction is computed. An uncertainty analysis was undertaken in order to give an indication of the confidence of the measured data. The 95\% confidence intervals were estimated for the measured and calculated results, following the procedures outlined in the ASME PTC19.1 standard. The set up for the wear set up for a tribology test is previously reported in detail in [5].

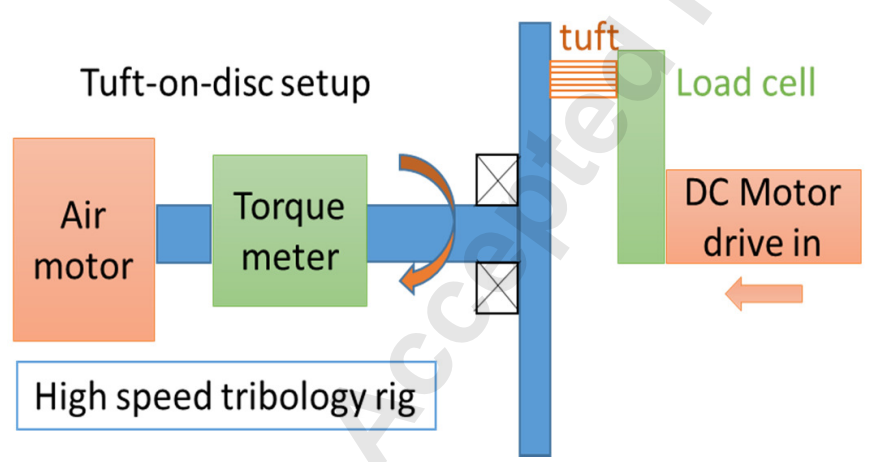

Fig. 3 Schematic of the high speed pin-disc tribology test rig

A Haynes 25 solid pin and bristle tuft of equal outer diameter have been tested sliding against a rotating disc of industrial gas turbine rotor material. Unfortunately, it proved impossible to measure the tuft-on-disc contact temperature directly during the tests. To provide such information, an FLIR thermal camera (model ThermoVision A20) was focused on the front and back surfaces of the rotating disc. Matt black paint (emissivity 0.952) was sprayed on to non-contacting parts of the disc and the pin/tuft surface, in order to maximise surface emissivity for the temperature measurement on the disc surface. It is recognised that the emissivity along the rubbing track will have a changing and lower emissivity, and provides only indicative temperature distributions, whereas the camera response can be calibrated for the painted areas. The temperature pickup of the surrounding air and other surfaces is minimal.

\section{NUMERICAL ANALYSIS}

\subsection{Anisotropy heat conductivity in tuft}

The anisotropy of the bristle bundle conductivity has been evaluated for the pseudo radial direction using a 2D FEM model. A rectangular domain of circular bristles with air gaps, is used to simulate heat transfer within a portion of tuft. It is assumed that the tuft is in a perfect hexagonal layout and the bristles are ideal circular shapes and equally-spaced. The side walls are adiabatic, and a constant temperature difference is applied between the top and bottom boundaries of the domain: this simulates effective 1D heat conduction. The gaps between bristles are filled with stationary air. Simulations are run until residuals lie below $1 \times 10^{-8}$ using an iterative linear algebraic solver. Furthermore, the convergence of the simulation is checked by the consistency of inbound and outbound heat fluxes.

Since the contact width and the bristle diameter are of different orders of magnitude, it is essential to build the geometry and mesh with precise contact width between bristles. The mesh used in this numerical study is generated by Gmsh, an open source meshing tool. The contact width is affected by a reduction of the distance between the centre of nearby contacting bristles, a Boolean union operation is used to fuse contacting bristles (circular shapes) into a single body with a prescribed contact width. To achieve the geometric accuracy required, the small section of each bristle in contact is modelled as a separate arc with deterministic starting and ending points, linked with other arcs describing the remaining bristle circumferences. The local mesh near the bristle contact area is detailed in Fig. 4, the contacting width being calculated using Hertzian contact theory without inter-bristle friction, see Eq. (26).

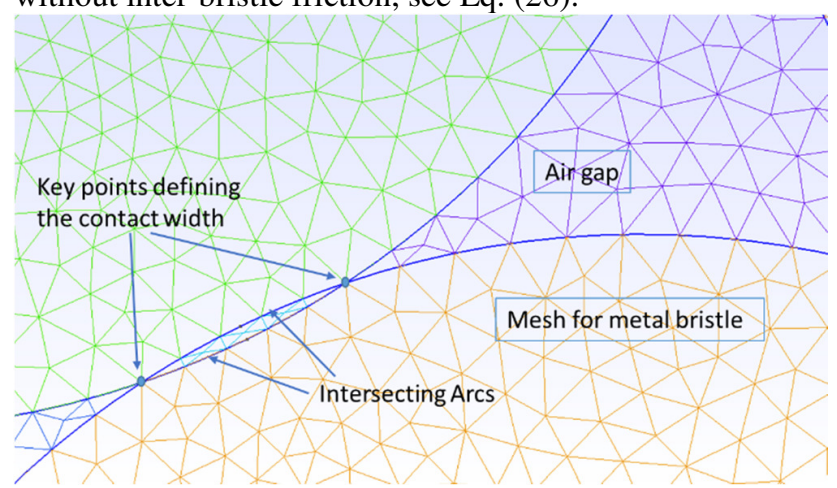

Fig. 4 meshing for Contact in a bristle tuft 
Another challenge of this calculation is to represent the distinct conductivity for different material domains, i.e. the metal bristles and air gaps. For the multi-scale meshing domain, it is important to set material properties to be discontinuous between different domains. In this numerical study, the thermal conductivity is represented using Discontinuous Galerkin finite elements, which keep function values at the cell centre to avoid the smoothing that would occur at mesh vertices between the air and metal. A Continuous Galerkin function space of degree 1 is used to solve the temperature field Fig. 5.

First of all, this in-house 2D FEM solver is validated by an analytical solution. Setting the thermal conductivity for air gap regions the same as the bristle area, the total heat flux is found equal to the analytical solution in a bulk metal plate for a given thermal gradient. The tuft heat flux ratio is independent of bristle radius, but the ratio of the inter-bristle indentation or gap over bristle radius. Only a portion of bristles cut by horizontal and vertical lines passing bristle centres is used to evaluate heat flux, due to the geometrical periodicity, see Fig. 5. It is confirmed by a $0.01 \%$ deviation of flux ratio for tuft portions for $5 \times 5,7 \times 7,5 \times 9$ and $9 \times 5$ columns and rows. A smaller physical domain of $5 \times 5$ is adopted to reduce the computational cost. Finally, mesh density independency is reached when the length ratio of cell characteristic length to the contact width is equal to 0.125 .

The FEM model was used to determine the effect of bristle packing on ETC by reducing the distance between neighbouring bristle centres. Fig. 6 shows the thermal conductivity ratio of bristle tuft to bulk bristle material as the distance between bristle centres is reduced. The bulk conductivity ratio of metal to the air is over 600, and thus ETC drops dramatically when the metal bristles are no longer in contact. From the bristle indentation / radius -0.0025 (separated by gap) to +0.0025 (in contact), there is an order of magnitude rise in ETC, see Table 2. The effect of air conductivity is also clearly seen, however the effect is small, being about $10 \%$ of the drop from contacting to non-contacting conditions.

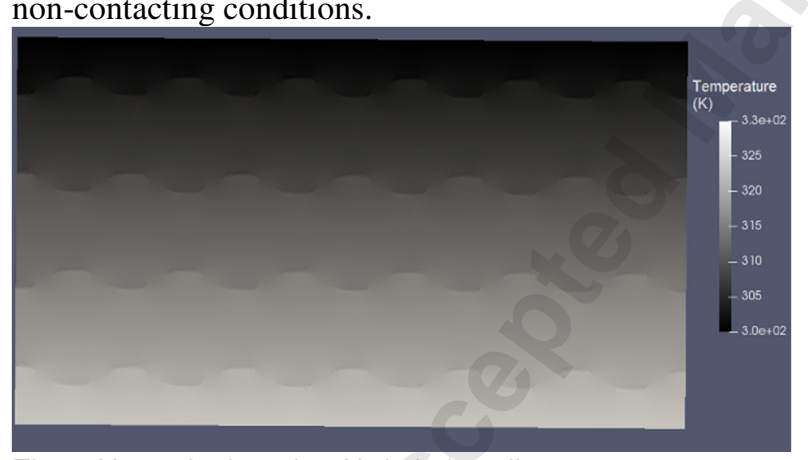

Fig. 5 Numerical study of bristle bundle temperature contour

Table 2 ETC dependency on contacting pressure

\begin{tabular}{|l|l|l|l|l|}
\hline $\begin{array}{l}\text { Contacting } \\
\text { pressure } \\
(\mathrm{MPa})\end{array}$ & $\begin{array}{l}\text { Indentation } \\
\text { ratio }\end{array}$ & $\begin{array}{l}\text { Perimeter } \\
\text { ratio }\end{array}$ & $\begin{array}{l}\text { ETC } \\
\text { ratio }\end{array}$ & $\begin{array}{l}\text { Filling } \\
\text { ratio }\end{array}$ \\
\hline NA & $-1.00 \mathrm{E}-02$ & NA & 0.0497 & 0.889 \\
\hline NA & $-2.50 \mathrm{E}-03$ & NA & 0.0979 & 0.902 \\
\hline
\end{tabular}

\begin{tabular}{|l|l|l|l|l|}
\hline 212 & $2.50 \mathrm{E}-03$ & 0.135 & 0.624 & 0.911 \\
\hline 846 & $1.00 \mathrm{E}-02$ & 0.271 & 0.723 & 0.922 \\
\hline
\end{tabular}

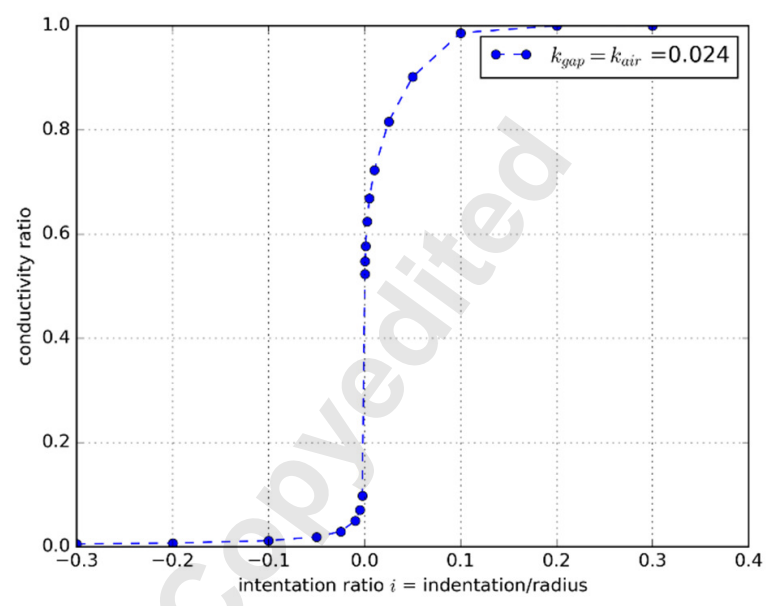

Fig. 6 ETC variates with the ratio of bristle gap or indentation to bristle radius

In this 2D numerical evaluation, material fusion is assumed for Hertzian contact of perfectly smooth cylindrical bristle surfaces. However, due to the imperfect layout and non-uniform bristle radius, point contacts in 3D space are expected instead of a continuous line contact. A typical ratio of inter-bristle gap to bristle radius, of 0.2 , is used in porous medium simulations for brush seals [19], reflecting a random distribution of bristle contacts at local asperities. Without microscopic observation of the bristle surface, the ETC can only be estimated. For the current analysis we will assume asperity contacts along $10 \%$ the ideal line contact i.e. $r_{\text {contact }}=10 \%$, with the remainder of the line separated by $0.2 r_{\mathrm{p}}$. The implication is then that the contacting pressure is $1 / r_{\text {contact }}$ times higher at the asperity contact than the uniform case. The impact of 3D asperity contact on ETC can be evaluated as.

$$
\mathrm{ETC}=\left(1-r_{\text {contact }}\right) k\left(i_{1}\right)+r_{\text {contact }} k\left(i_{2}\right)
$$

where $k(i)$ is found by curve-fitting the conductivity ratio as a function of the indentation ratio. Since this non-linear function has a steep gradient at zero, the small portion of 3D contact with higher contacting pressure has a very limited contribution to ETC compared to the non-contacting area. Thus, ETC of the clamped tuft is estimated to be one order magnitude lower the bulk metal conductivity.

The anisotropic conductivity tensor $K$ is represented by $k_{\mathrm{r}}$ and $k_{\mathrm{z}}$, the effective thermal conductivity in radial and axial directions respectively. In this paper, $k_{\mathrm{r}}=0.1 \times k_{\text {metal }}$ and $k_{\mathrm{z}}=0.9 \times$ $k_{\text {metal }}$ are adopted to evaluate the thermal distribution of tuft-ondisc system.

$$
K=\left[\begin{array}{ccc}
k_{r} & 0 & 0 \\
0 & k_{r} & 0 \\
0 & 0 & k_{z}
\end{array}\right]
$$




\subsection{FEM solver for quasi-static heat transfer}

For the finite element analysis of the rotating disc without the static pin/tuft, frictional heating at the contact is conventionally simplified into a constant heat flux boundary condition on the annular track for high Peclet numbers, while static heat flux boundary condition is applied on contact area for low Peclet numbers. However, thermal distribution on the disc for the intermediate rotating speeds/Peclet numbers cannot be simulated by those simplifications. Directly solving the quasistatic heat transfer problem in Eq. (8) can obtain the temperature distribution near the contact area, without any assumption on Peclet number.

In this paper, the quasi-static heat transfer of the rotating system is solved for the first time, using an in-house FEA solver ${ }^{1}$ [20]. This in-house solver was validated using the commercial FEM module ANSYS Workbench v. 14.5, for an annular heat source situated on the sliding track and also compared to a static heat input which should have an identical thermal distribution. Applying a quasi-static model and static heat flux at the contact, the solver was found to generate an identical temperature distribution given by the static solver at $\mathrm{Pe}=2450$. The solution was found also to be qualitatively similar to the temperature distribution of Laraqi et al. [7] at low Peclet numbers.

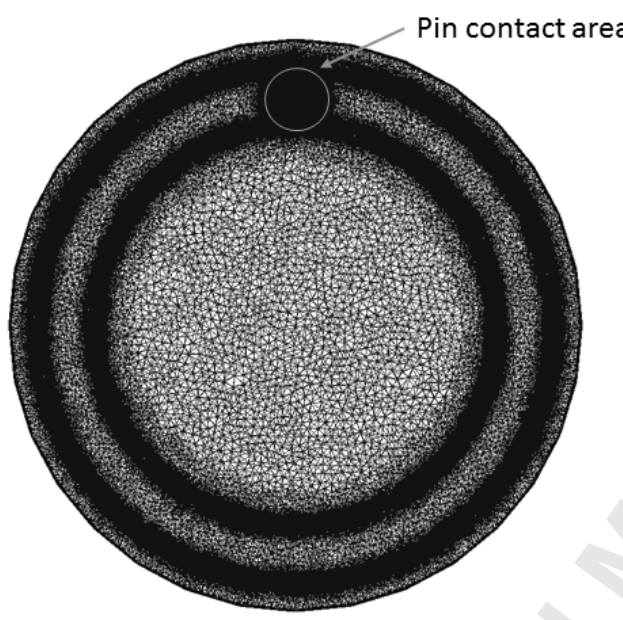

Fig. 7 Mesh for rotating disc with refinement near track and contact

The mesh is refined at the point of contact and on either side of the sliding track to capture the highest temperature gradients near the track, as shown in Fig. 7. Mesh independency checks were conducted on three meshes with 1.1, 2.8 and 6.0 million first-order tetrahedral cells, which confirmed the variation in average temperature at the contact is less than $0.1 \%$ between the medium and finest meshes. Therefore, the mesh with 2.8 million cells was used in all subsequent numerical studies reported here.

While the heat input above was confined to the disc, it is quite possible to introduce a heat source at the pin/tuft on disc interface and solve the heat transfer to the assembly of the static pin/tuft and the rotating disc simultaneously, without any assumption concerning the heat partitioning. The quasi-static heat transfer equation is solved in the domain of the rotating disc, while steady heat transfer equation is solved within the pin. Simultaneously modelling of both the static and moving parts in a single mesh can calculate the heat partition coefficient directly, and is capable of dealing with non-uniform heat generation on the rubbing interface and convective heat dissipation on the pin and disc surfaces. The heat generation is modelled as a thin layered volumetric source, and thereby, the temperature field is not discontinuous at the contacting interface. This treatment is further validated by matching the heat generation to the total convective heat dissipation on the disc and pin surfaces.

Frictional heating is generated from the tribo-pair interface which may have micron or sub-micron thickness [14] in reality. While this layer is probably thermally thin, the layer thickness is important in obtaining a reliable solution. In this study, the heat partitioning dependency on heating layer thickness is numerically evaluated. It is found that heat partitioning is independent of heating thickness, provided the heating layer thickness is one order of magnitude less than the disc thickness and the pin height in this study. The heating layer is modelled as $10 \mu \mathrm{m}$ thick. The thermal properties of the layer were considered equal to the pin / tuft material.

Table 3 shows the geometrical parameters and material properties for a stainless steel disc, used in this numerical simulation (after Fig. 7). The pin's material is set as Haynes 25 and its material properties are listed in Table 3. A constant HTC boundary condition is set on both sides of the rotating disc. For the laminar boundary layer on the rotating disc, Eq. (11) indicates HTC is homogenous on the disc and it is only a function of the rotating speed whereas for a turbulent boundary layer, HTC is a function of both radial position and rotating speed.

\subsection{Quasi-static solution vs static annular heating source}

Table 3 Parameters for modelling thermal distribution of pin on disc

\begin{tabular}{|l|l|l|}
\hline & Quantity name & Quantity (S.I.) \\
\hline$r_{\mathrm{d}}$ & Disc radius & $0.1[\mathrm{~m}]$ \\
\hline$r_{\mathrm{p}}$ & Pin radius & $0.01[\mathrm{~m}]$ \\
\hline$t_{\mathrm{d}}$ & Disc thickness & $0.005[\mathrm{~m}]$ \\
\hline$e / r_{\mathrm{d}}$ & Eccentricity of pin & 0.8 \\
\hline$h_{\mathrm{d}}$ & Convective heat & $100\left[\mathrm{~W} /\left(\mathrm{m}^{2} \cdot \mathrm{K}\right)\right]$ \\
$h_{\mathrm{p}}$ & coefficient & \\
\hline$\rho$ & Density & $7800\left[\mathrm{~kg} / \mathrm{m}^{3}\right]$ \\
\hline$k_{\mathrm{d}}$ & Thermal conductivity & $16[\mathrm{~W} /(\mathrm{m} \cdot \mathrm{K})]$ \\
\hline$c_{\mathrm{p}}$ & Heat capacity & $480[\mathrm{~J} /(\mathrm{K} \cdot \mathrm{kg})]$ \\
\hline $\mathrm{Bi}_{\mathrm{d}}$ & Biot number & 0.625 \\
\hline
\end{tabular}

Depending on Peclet number, several thermal distribution patterns are observed on the disc surface with rubbing contact. Full temperature and thus temperature gradient distributions are

${ }^{1}$ https://github.com/qingfengxia/FenicsSolver using the open source FEM infrastructure Fenics version 2016.2 
essential for thermal stress evaluation in high speed rotating systems. In the following analyses, using a moving annular heat source, Peclet number is based on pin radius and pin sliding speed, see Eq. (7). Fig. 8 shows the temperature rise on the disc with increasing Peclet number. At low Peclet number, the quasistatic solution shows an elevated temperature rise at the local point of contact (see Fig. 8(a)).

In particular, the trailing edge (of the pin) has a higher temperature than the leading edge, and on the disc there is a local temperature profile along the length of the rubbing track. On the other hand, when the Peclet number is high (e.g. Fig. 8(c)), as commonly found in high speed pin-on-disc tests, a temperature difference between the pin-on-disc contact area and the sliding track is not apparent. Fig. 10 shows that the average temperature at the contact can be significantly higher for Peclet numbers near unity, with a continual drop with increasing Peclet number. There is a negligible difference for $\mathrm{Pe}>1000$, providing a criterion for a simplified thermal analysis.

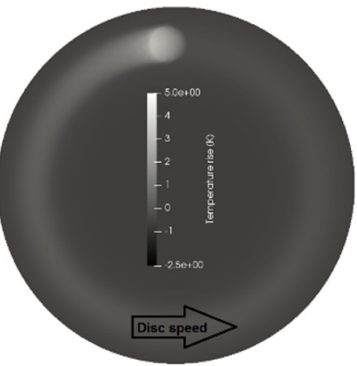

a) $\mathrm{Pe}=1.2$, front

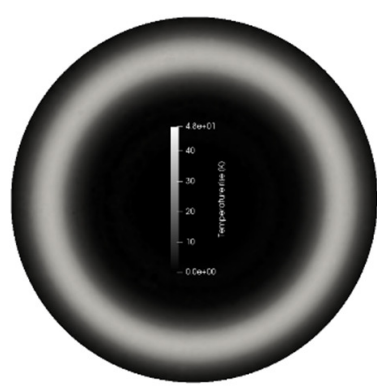

c) $\mathrm{Pe}=2450$, front

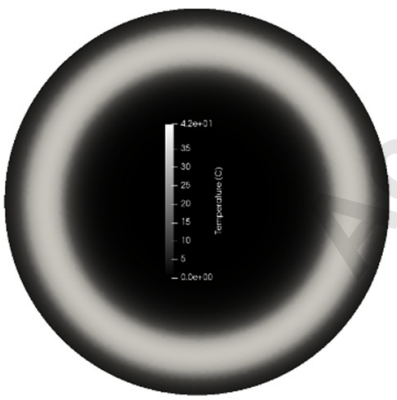

e) $\mathrm{Pe}=2450$, static, front, with convection on track

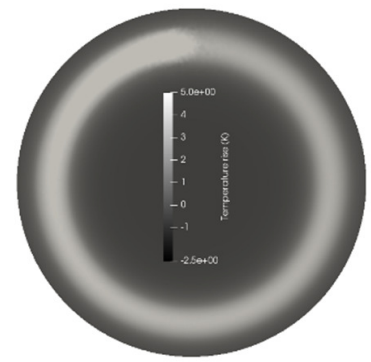

b) $\mathrm{Pe}=24.5$, front

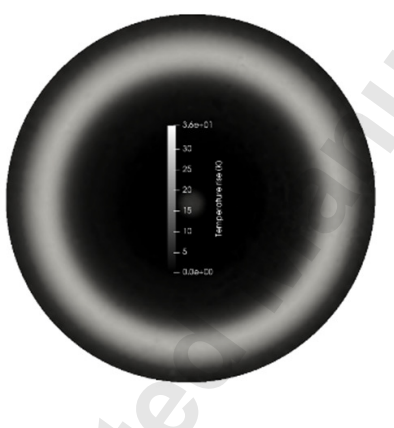

d) $\mathrm{Pe}=2450$, back

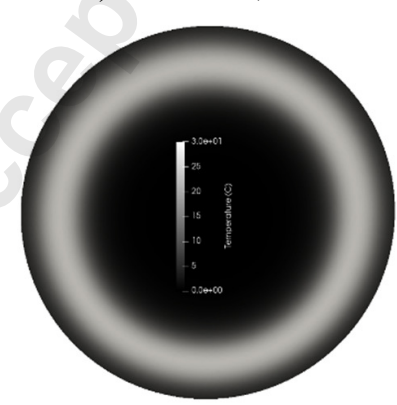

f) $\mathrm{Pe}=2450$, static, front without convection on track
Fig. 8 Contours of temperature rise based on ambient temperature for (a-d) quasi-static rotating heating source; (e-f) static case of annular heating flux with without convective heat transfer on the rubbing track

The rotating disc is not treated as a semi-infinite body. Thus, the convective cooling on all surfaces is critical to obtaining an accurate temperature distribution through its volume. It is observed that, in steady state tests, temperature rise distributions similar to the front face but with a lower track average temperature rise are found on the back surface of the rotor, as seen in Fig. 8 (c \& d).

Figure 9 suggests the temperature at the contact is higher than the average on the rubbing track at low Peclet numbers, tending to an axisymmetric distribution for Pe $>2450$. It follows that, at high Peclet numbers, a static case with an annular heat flux boundary should quickly and accurately simulate the thermal distribution on the disc; though the quasi-static model has an advantage in the precision of its solution over the static model, see Fig. 8 (c $c f$. e - $\mathrm{f}$ ). The nominal contact area is the cross-section of the pin, instead of the whole track as in the static case. If both heat flux and convective heat transfer boundary conditions are applied on the track, the maximum temperature on the track is lower than the quasi-static case, due to significant heat transfer from the track area into the ambient air flow. Ignoring the cooling effect of the convective heat transfer on the track surface, the temperature of the track is over-predicted by the static simulation. For the specific case of $\mathrm{Pe}=2450$, $\mathrm{Bi}_{\mathrm{p}}=0.625$ and a heating power partitioned such that $38 \mathrm{~W}$ flows into the disc, the deviations in the average temperature rise on the track are about $-15 \%$ and $10 \%$ for the static cases with and without convective heat transfer on the track respectively.

To apply both heat flux and convective heat transfer boundary conditions on the whole track, a heat flux correction ratio $(>1.0)$ applied to the nominal heating power is required to generate the same thermal distribution on the disc as in the quasistatic case at high Pe. An iterative process can be used to calculate the compensating ratio, such that the total heat flux entering the disc in the static case equals that from the pin-ondisc contact of the quasi-static case.

Biot number in the context of pin-on-disc thermal distributions represents how fast heat is lost through convection compared to its conduction through the solid. The length scale chosen for the disc Biot number is the disc radius, but the disc thickness has a significant impact on the thermal distribution and heat partition for the rotating disc. The average temperature rise on the rubbing track and the corresponding area on the back surface are compared; the ratio of the average temperature is shown in Fig. 10. The high Peclet number of 2450 is selected for consideration as the homogeneous temperature along the rubbing track makes analysis more straightforward. Two variables, disc thickness and convective heat transfer coefficient, are investigated numerically. For a very small convective heat coefficient on the disc, i.e. small $\mathrm{Bi}_{\mathrm{d}}$, the thermal distribution on both sides are similar. On the other hand, the high surface 
convective cooling leads to a large temperature difference; the small temperature ratios suggest cooling on the front surface is more significant. A dropping temperature ratio of the back and front track is found for increasing either the disc thickness or the convective heat transfer coefficient - i.e. raising the Biot number, and similar results would be expected if the rotor material were replaced with one of lower conductivity. In the context of conducting pin of disc experiments, a good understanding of Biot number is necessary if indirect measurements of the nominal contact temperature are to be made through monitoring of the back surface temperature during testing.

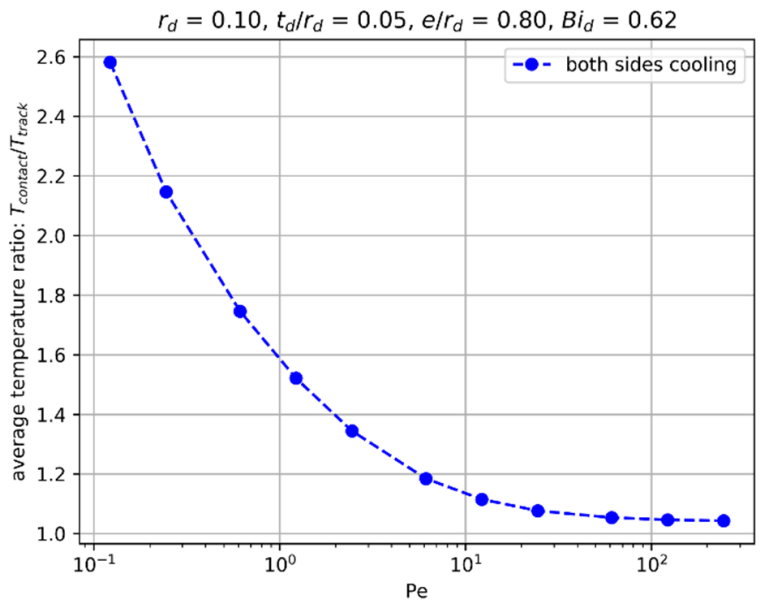

Fig. 9 Contact area average temperature ratio vs Peclet number

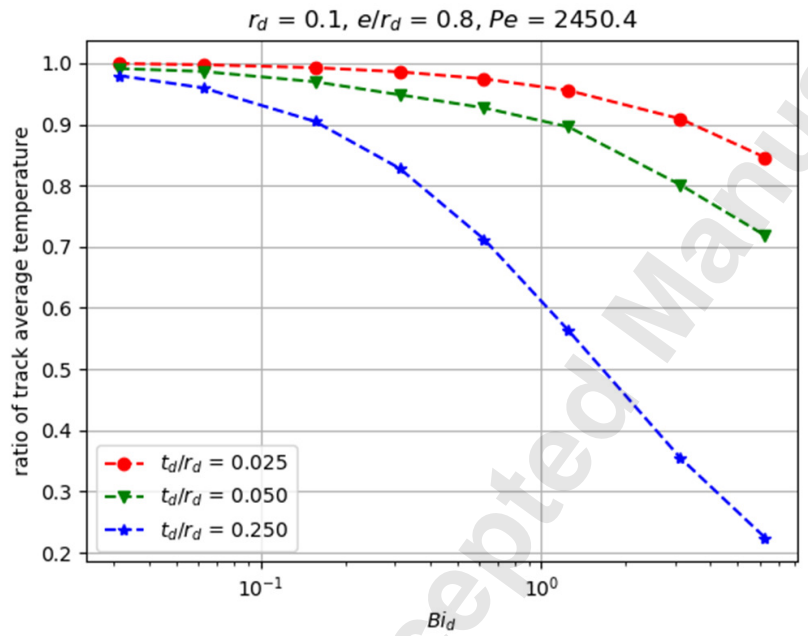

Fig. 10 Average temperate ratio on the track location for both sides of the rotating disc

\section{$\underline{4.4 \text { Heat partition coefficient }}$}

Existing analytical solutions for heat partition frequently use wide ranging assumptions to simplify the heat partition problem. One of these is to treat the pin and disc as semi-infinite cylinders. Such models $[14,15]$ link heat partition only to Pe, and where $\mathrm{Pe}$ is above a threshold value the heat partition coefficient is deemed to remain constant. In contrast, Laraqi's study [7] suggests that combination of $\mathrm{Bi}_{\mathrm{p}}$ and $\mathrm{Bi}_{\mathrm{d}}$ has a major impact on heat partition, but this study also has some underlying assumptions: namely a semi-infinite disc and an adiabatic disc rim. Making neither geometric assumptions nor simplifications of the thermal boundary conditions, this quasi-static FEM solver can solve the thermal distribution of any quasi-static system. In this numerical study, a pin was used rubbing on the front face of a rotating disc, but the rubbing interface could equally be on the cylindrical surface of a rotating component [21], e.g. a brake shoe on a drum, metal cutting on lathes, or a brush seal installed in an engine application. In addition, non-homogeneous thermal boundary conditions on the pin and disc, non-uniform heat generation on the contact area can be simulated by this quasistatic FEM solver.

The impact of the relative size of $\mathrm{Bi}_{\mathrm{d}}$ and $\mathrm{Bi}_{\mathrm{p}}$ is illustrated in Fig. 11 over a range of $\mathrm{Pe}, 1<\mathrm{Pe}<12,000$. A relatively long pin, $t_{\mathrm{p}} / r_{\mathrm{p}}=10$, was used to compare the current model to reported results using a semi-infinite pin length (Archard's analytical solution), while a thin disc is commonly adopted for high rotating speed tests. The baseline geometrical parameters and material properties are listed in Table 4 . Thermal conductivities for disc and pin material are similar, but the disc radius is one order of magnitude larger than that of the pin. Considering the higher HTC on a rotating disc, the pin Biot number should be at least one order of magnitude smaller than that of a disc as normally employed.

In the results shown in the figure the baseline disc Biot number is 0.625 , and the $\mathrm{Bi}_{\mathrm{p}}$, and is fixed at an arbitrarily low value of 0.1 . The effect of Peclet number is seen to be small at all but very low Peclet numbers $(\mathrm{Pe}<100)$. The effect of disc Biot number on heat partition is seen by increasing and decreasing $\mathrm{Bi}_{\mathrm{d}}$ by an order of magnitude. The heat partition coefficient is seen to be very sensitive to dropping disc Biot number, as this will result in a more homogeneous disc temperature. Somewhat surprisingly it is found that the Biot number is, in fact a more important driver of heat partition than the Peclet number. Archard's solution of heat partition coefficient is shown to follow an entirely different trajectory. It ignores the impact of changing thermal boundary conditions on heat partition, leading to substantial errors at low Peclet numbers. Differences between the solid pin and the bristle tuft are only observable at small $\mathrm{Bi}_{\mathrm{d}}$. Due to lower ETC especially in the tuft radial direction compared to the pin, the smaller effective tuft Biot number shifts the curve of heat partition coefficient upwards slightly. 


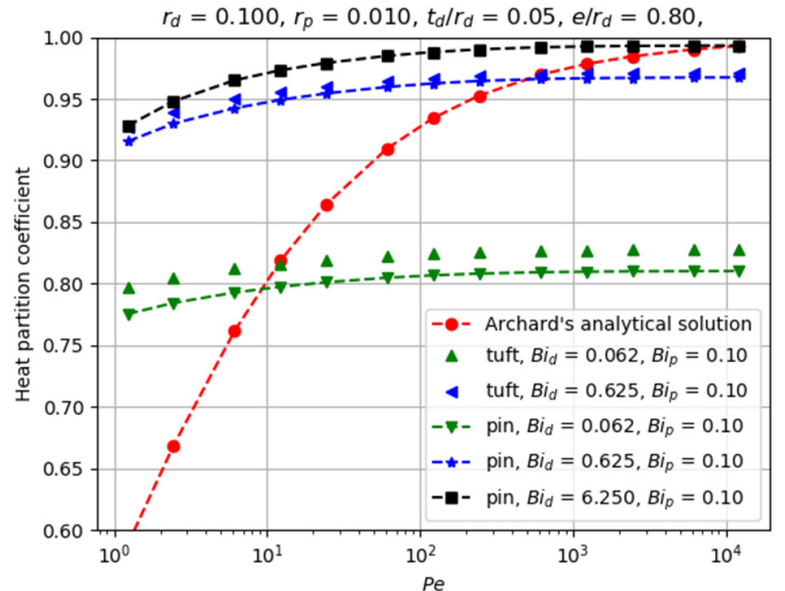

Fig. 11 Heat partition coefficient sensitivity to $\mathrm{Pe}, \mathrm{Bi}_{\mathrm{d}}$ and $\mathrm{Bi}$, $t_{p} / r_{p}=10$

The pin height also affects heat partition, see Fig. 12 (a). A large Peclet number 2450 is selected to evaluate the impact of pin height on heat partitioning, so that heat partition is not sensitive to Peclet number. Apparently, the smaller convective dissipation surface of a shorter pin leads to a higher partition coefficient. The impact disappears if the pin's height to radius ratio is larger than the reciprocal of $\mathrm{Bi}_{\mathrm{p}}$. Furthermore, replacing the solid pin with a bristle tuft also increases heat partition coefficient, but the difference is negligible if $\mathrm{Bi}_{\mathrm{d}}>\mathrm{Bi}_{\mathrm{p}}$ for high speed tribology tests.

Figure 12 (b) shows the impact of disc thickness and of disc Biot number when the HTC changes. For a typical high speed pin-on-disc tribology configuration, the impact of the disc HTC boundary condition on heat partitioning is limited for $\mathrm{Bi}_{\mathrm{d}}>\mathrm{Bi}_{\mathrm{p}}$. Increasing the disc thickness can substantially alter the thermal distribution on the disc surfaces - due to the change in the overall heat capacity, but its impact on the heat partition is not evident except at low $\mathrm{Bi}_{\mathrm{d}}$. For a low $\mathrm{Bi}_{\mathrm{d}}$ (due to low HTC), the increased disc total surface temperature can increase the capacity of the disc to store heat. Thereby, a thicker disc increases the heat partition coefficient. This mechanism is different to that of Laraqi's solution in which the disc $\operatorname{rim} r=r_{\mathrm{d}}$ is adiabatic, and the increased thickness does not change the solution as a semiinfinite body is already assumed.

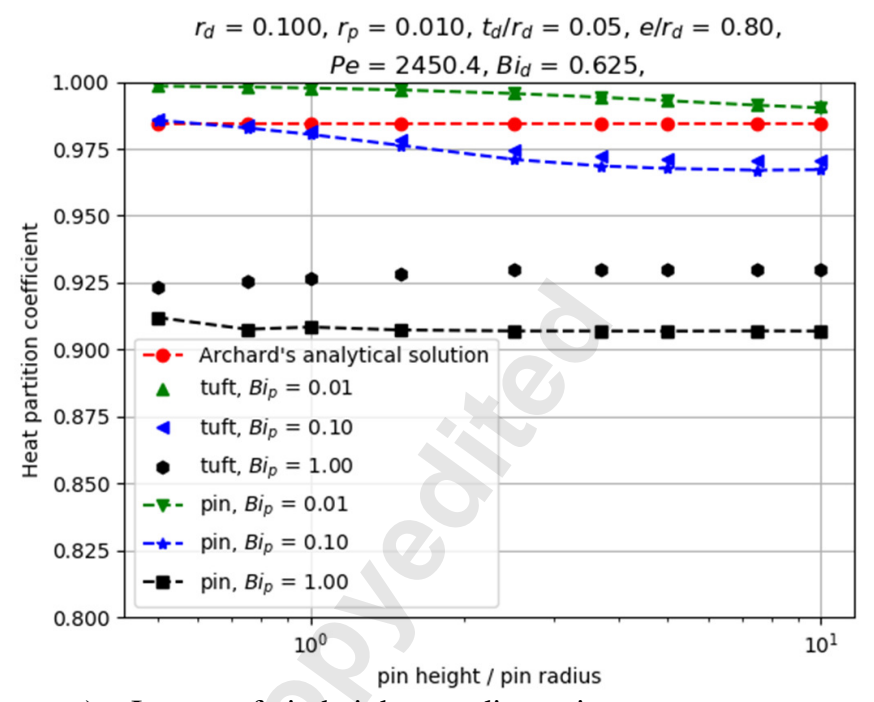

a) Impact of pin height to radius ratio

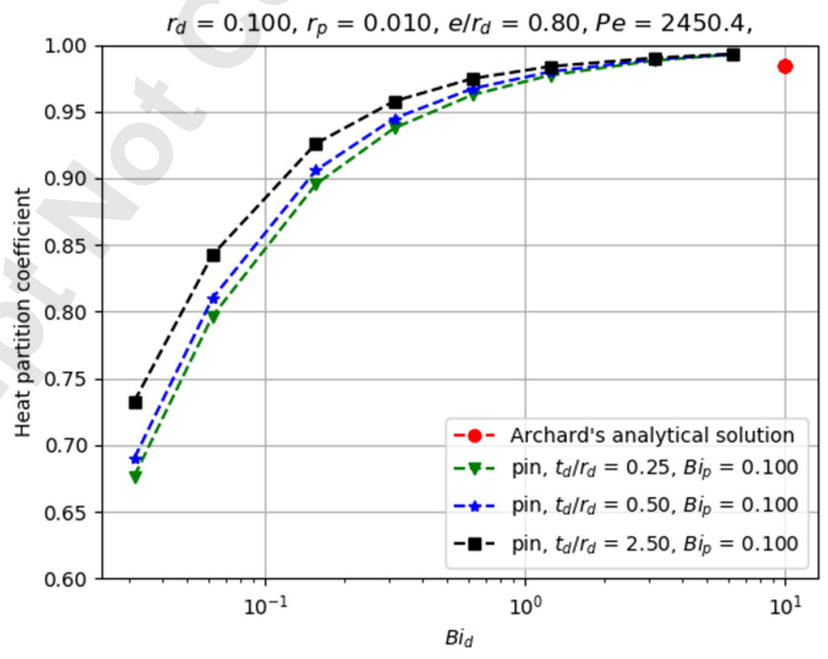

b) Impact of disc thickness

Fig. 12 Heat partition coefficient sensitivity to geometry and thermal boundary condition for the pin-on-disc rubbing system

For a solid pin on the rotating disc, a multi-variable fitting of heat partition coefficient $\boldsymbol{p}_{\boldsymbol{d}}$ has identified relative contribution from each dimensionless parameter.

$$
p_{d}=0.88 \mathrm{Pe}^{0.0044}\left(\frac{t_{d}}{r_{p}}\right)^{0.0065}\left(\frac{t_{p}}{r_{p}}\right)^{-0.0025} \mathrm{Bi}_{d}^{0.048} \mathrm{Bi}_{p}^{-0.024}
$$

This correlation is good for identifying the key drivers of heat partition, but is not sufficiently precise to use as a design tool. It illustrates that disc and pin Biot number is the dominant driver of heat partition.

\subsection{Thermal distribution for tuft-on-disc configuration}

Figure 13 shows validation of the current numerical model using several high speed tuft-on-disc wear tests. The local disc Reynolds number of 490,000 lies in the fully turbulent flow 
regime, and a non-uniform HTC on disc surface is applied, using Eq. (11). HTC is near constant near the disc centre, increasing with radial location in through transition and turbulent flow regimes. The calculated temperature rise plus the adiabatic temperature (Fig. 13(b)) is compared to the thermography measurements viewed through a hole in the rig containment shown in Fig. 13(a). The temperature rise is in agreement within a discrepancy of $3 \%$, with a carefully-selected reference temperature, i.e. adiabatic temperature without tuft contact. The thermal distribution pattern also agrees with the experiment; higher temperature is found on the disc rim and lower at the centre. Furthermore, a metal hood, used as the rig containment over the rotating disc, increases the entrainment of flow into the boundary layer and causes partial flow recirculation. The impact on the thermal boundary condition is to accelerate turbulent boundary layer transition. The thermal boundary condition for the tuft can be complicated, but its impact on the interface temperature and heat partition at high Peclet numbers can be neglected, according to the heat partition analysis in the previous section.

Admittedly, it is challenging to select the proper reference temperature for the heat transfer coefficient in Eq. (11). For the high rotating speeds in this study, significant temperature rise due to viscous heating has been observed by infra-red thermography on the back surface without tuft contact. This measured temperature at the point of interested (tuft eccentricity) is a representative value for the adiabatic temperature. There is a formula $T_{\text {adiabatic }}=\operatorname{Pr}^{0.33} V^{2} / 2 c_{p}$ to predict the adiabatic temperature in the laminar regime [9], while good agreement is observed in the turbulent regime in the current test, see Fig. 14. Ambient temperature near the rotating disc is monitored by thermocouples at multiple positions, but they are found not appropriate as the reference temperature.

Using the adiabatic temperature without tuft contact as the reference temperature for the convective heat transfer in Eq. (11), the numerical predictions of the maximum temperature on the back surface are seen to match experimental results well, except for the cases at the lowest and highest tested Reynolds numbers where there is a difference of $\sim \pm 2{ }^{\circ} \mathrm{C}$. At the lowest Reynolds number, the FEA underestimates the temperature rise. This is expected that heavy frictional heating raises the real adiabatic wall temperature, which has the effect of reducing cooling in the experimental case. Additionally, frictional heating and recirculation may raise the temperature inside the rig containment further reducing the cooling potential. At the other extreme, $\operatorname{Re}=9.1 \times 10^{5}$, the windage and frictional heating are higher. Here as the disc is of the same thermal mass and the equilibrium achieved is dependent on the difference between the frictional and windage heating and the convective cooling, an error in the HTC level has a larger impact on the final temperature rise - seemingly an over-prediction for the correlations used.

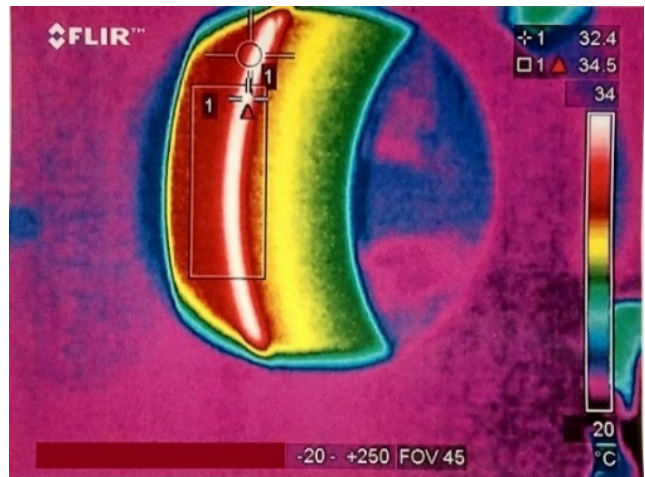

a) Infra-red camera measurement on front track

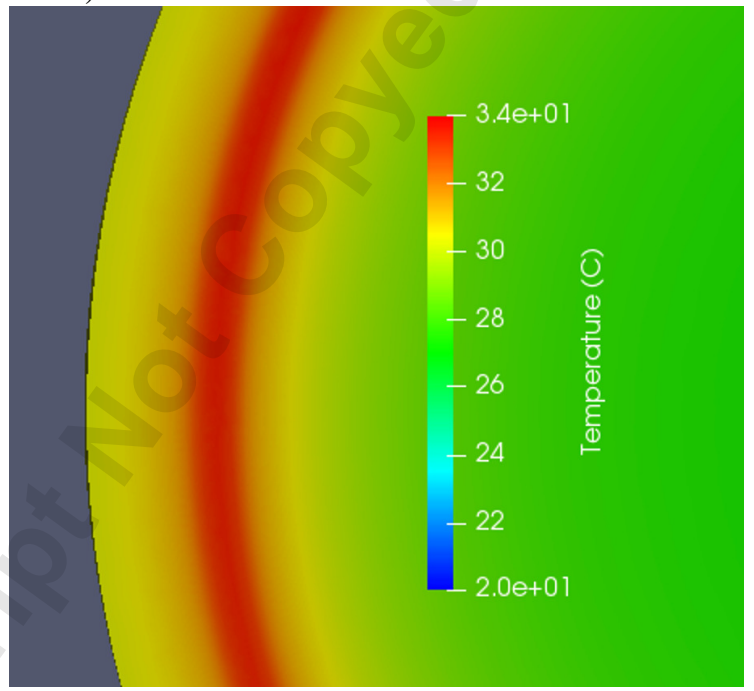

b) Numerical prediction

Fig. 13 Validation of numerical model with thermal measurement for high speed tuft-on-disc rubbing, $e / r_{d}=0.88$, $t_{\mathrm{d}} / r_{\mathrm{p}}=1, \mathrm{Pe}=5.5 \times 10^{4}, \mathrm{Re}=4.9 \times 10^{5}, T_{\text {reference }}=23^{\circ} \mathrm{C}$

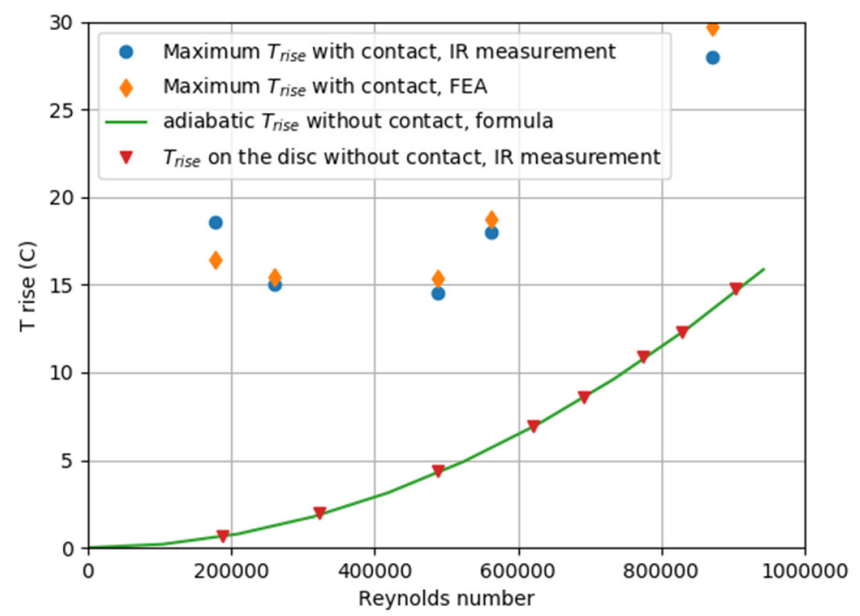

Fig. 14. Validation of numerical prediction of maximum temperature rise on the back surface of the disc

From the FEA model it is possible to predict the track temperature, based on the temperature measurement of the back 
surface of the rotating disc. Fig. 15 shows a significant difference in the maximum temperature between the front and back surfaces. It should be noted that while it is possible to obtain high accuracy infra-red temperature measurements on the back surface by applying black matt paint of known emissivity and calibrating the system, the rubbed front surface remains polished and obtaining direct IR temperature measurements here is, in effect, impossible. Thus this hybrid method provides the best route to understanding the rubbing track nominal temperature, allowing further analysis on local asperity temperatures on that tuft surface.

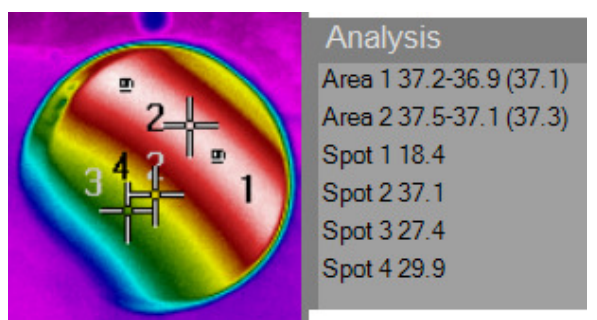

a) Infra-red camera measurement on the back surface

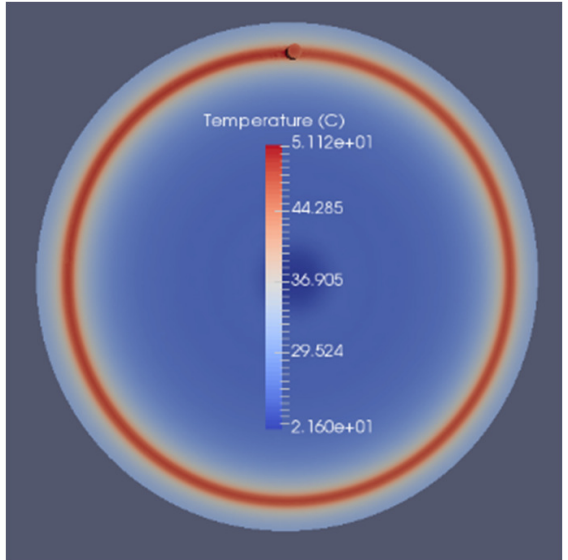

b) Numerical prediction, front surface

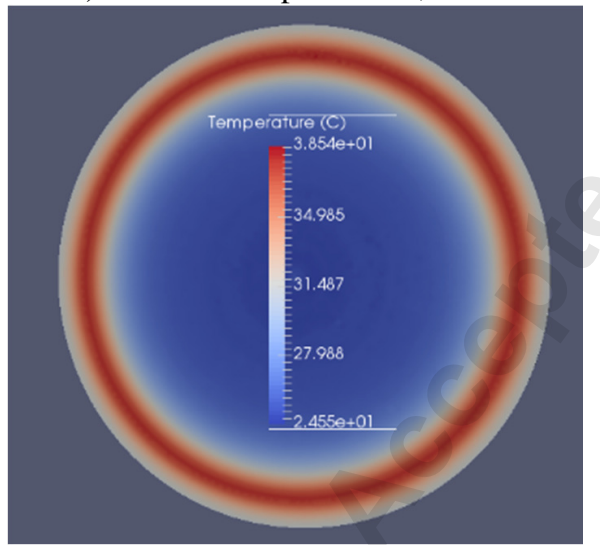

c) Numerical prediction, back surface

Fig. 15 Experimental and numerical prediction of temperature distribution on the disc, $e / r_{d}=0.88, t_{d} / r_{p}=1, P e=1.5 \times 10^{5}$,

$\mathrm{Re}=5.6 \times 10^{5}, T_{\text {reference }}=25^{\circ} \mathrm{C}$

\section{CONCLUSION}

In this paper, the quasi-static thermal distribution and heat partition for the pin-on-disc and tuft-on-disc configurations, and the effective thermal conductivity of a metal bristle bundle are numerically evaluated. The quasi-static in-house solver has several advantages over the existing analytical or iterative approaches:

(1) this reduced-order model dispenses with the computational cost of transient simulations;

(2) more realistic thermal boundary conditions such as non-uniform heat generation and surface convective heat coefficient can be applied;

(3) a quasi-static solver without limit on Peclet number range;

(4) realistic pin/tuft and disc geometry can be simulated simultaneously without semi-infinite thickness assumptions, which leads to significant error in heat partition for a thin disc; (5) the heat partition coefficient can be calculated directly from the ratio of the heat flux exiting the disc and total heat generation.

The modelling has confirmed that a static annular heat flux can simulate the thermal distribution for $\mathrm{Pe}>1000$. For the homogenous heat generation at such high Peclet numbers, no angular thermal gradient on the track is found. For lower Peclet numbers, the temperature on the contact is higher than other place on the sliding track. Care must, however, be taken in applying convective boundary conditions in these calculations.

The heat partition coefficient is found not only sensitive to Peclet number, disc and pin/tuft Biot number, but also disc thickness and pin/tuft height. If pin height is larger than the reciprocal of the pin Biot number, its impact on the heat partition can be neglected.

Furthermore, the anisotropy of heat transfer within tightly bundled bristles is evaluated for various bristle contact conditions. The heat transfer along the bristle length is not significantly affected since the filling ratio approaches unity, unlike the effective heat conductivity in the bristle radial direction which is heavily dependent on the contact pressure and gap length scale. It is estimated that ETC in the radial direction is one order of magnitude smaller the bulk metal material, however it is recognised that further work is required to accurately measure this. For a typical high speed tuft-on-disc test condition, the disc Biot number $>>$ pin Biot number, and thus replacing the solid pin by a tuft does not significantly affect the average contact temperature and heat partition in a tribology test.

\section{ACKNOWLEDGMENTS}

The work was funded by Rolls-Royce and through the Innovate UK / ATI SILOETII programme. The expert work in the manufacture and maintenance of the test rigs by Mr. Leo Verling is greatly appreciated

\section{NOMENCLATURE}

$\begin{array}{ll}\text { Symbol } & \text { Name and unit } \\ A & \text { Contact area }\left[\mathrm{m}^{2}\right] \\ c_{p} & \left.\text { Heat capacity }\left[\mathrm{J} \mathrm{K}^{-1} \mathrm{~kg}^{-1}\right)\right] \\ d & \text { Indentation depth between bristles }[\mathrm{m}]\end{array}$




\begin{tabular}{|c|c|}
\hline$e$ & Eccentricity of pin [m] \\
\hline E & Elastic modulus [Pa] \\
\hline$F$ & Contact force $[\mathrm{N}]$ \\
\hline$h$ & Convective heat coefficient $\left.\left[\mathrm{W} \mathrm{m} \mathrm{m}^{-2} \mathrm{~K}^{-1}\right)\right]$ \\
\hline$i$ & Indentation ratio \\
\hline$k$ & Thermal conductivity $\left[\mathrm{W} \mathrm{m} \mathrm{m}^{-1} \mathrm{~K}^{-1}\right.$ ] \\
\hline$L$ & Length $[\mathrm{m}]$ \\
\hline$t$ & Disc thickness, pin height $[\mathrm{m}]$ \\
\hline$p$ & Pressure $[\mathrm{Pa}]$ \\
\hline$p_{d}$ & Thermal partition ratio \\
\hline$q$ & Heating power rate $[\mathrm{W}]$ \\
\hline$r$ & Disc radius, radial position $[\mathrm{m}]$ \\
\hline$R$ & Thermal resistance $\left[\mathrm{K} \mathrm{W}^{-1}\right]$ \\
\hline & Ratio \\
\hline$T$ & Temperature $[\mathrm{K}]$ \\
\hline$V$ & Velocity $\left[\mathrm{m} \mathrm{s}^{-1}\right]$ \\
\hline$w$ & Width of contact $[\mathrm{m}]$ \\
\hline$\alpha$ & Thermal diffusivity $\left[\mathrm{m}^{2} \mathrm{~s}^{-1}\right]$ \\
\hline$\lambda$ & Thermal conductivity $\left[\mathrm{W} \mathrm{m} \mathrm{m}^{-1} \mathrm{~K}^{-1}\right.$ ] \\
\hline$\theta$ & Angular position $[\mathrm{rad}]$ \\
\hline$\rho$ & Density $\left[\mathrm{kg} \mathrm{m}^{-3}\right]$ \\
\hline$\omega$ & Angular velocity [ $\left.\mathrm{rad} \mathrm{s}^{-1}\right]$ \\
\hline$v$ & Kinematic viscosity $\left[\mathrm{m}^{2} \mathrm{~s}^{-1}\right]$ \\
\hline & Poisson ratio [1] \\
\hline & Dimensionless number: \\
\hline $\mathrm{Bi}$ & Biot number \\
\hline $\mathrm{Kn}$ & Knudsen number \\
\hline $\mathrm{Nu}$ & Nusselt number \\
\hline $\mathrm{Pe}$ & Peclet number \\
\hline $\operatorname{Pr}$ & Prandtl number \\
\hline $\mathrm{Re}$ & Reynolds number \\
\hline & Subscripts: \\
\hline d & disc \\
\hline $\mathrm{n}$ & pin \\
\hline
\end{tabular}

ETC Effective Thermal Conductivity

HTC Heat Transfer Coefficient

\section{REFERENCES}

[1] Steinetz, B. M., Hendricks, R. C., and Munson, J., 1998, Advanced seal technology role in meeting next generation turbine engine goals, Citeseer.

[2] Conner, K., and Childs, D., 1992, "Rotordynamic and leakage characteristics of a 4-stage brush seal," DTIC Document.

[3] Fellenstein, J. A., and DellaCorte, C., 1996, "A new tribological test for candidate brush seal materials evaluation,"

Tribology transactions, 39(1), pp. 173-179.

[4] Hawthorne, H., 1994, "Brush-on-disc simulation tribotesting of materials for gas turbine-compliant seal components," Tribology international, 27(2), pp. 87-95. [5] Thakare, M., Mason, J., Owen, A., Gillespie, D., Wilkinson, A., and Franceschini, G., 2016, "Effect of sliding speed and counterface properties on the tribo-oxidation of brush seal material under dry sliding conditions," Tribology International, 96, pp. 373-381.

[6] Mendes, M. A., Ray, S., and Trimis, D., 2013, "A simple and efficient method for the evaluation of effective thermal conductivity of open-cell foam-like structures," International Journal of Heat and Mass Transfer, 66, pp. 412-422.

[7] Laraqi, N., Alilat, N., de Maria, J. G., and Baïri, A., 2009, "Temperature and division of heat in a pin-on-disc frictional device-exact analytical solution," Wear, 266(7), pp. 765-770. [8] Bayley, F., Long, C., and Turner, A., 1993, "Discs and drums: the thermo-fluid dynamics of rotating surfaces,"

Proceedings of the Institution of Mechanical Engineers, Part C: Journal of Mechanical Engineering Science, 207(2), pp. 73-81. [9] Harmand, S., Pellé, J., Poncet, S., and Shevchuk, I. V., 2013, "Review of fluid flow and convective heat transfer within rotating disk cavities with impinging jet," International Journal of Thermal Sciences, 67, pp. 1-30.

[10] Elkins, C. J., 1997, "Heat transfer in the rotating disk boundary layer."

[11] Shevchuk, I. V., 2009, Convective heat and mass transfer in rotating disk systems, Springer Science \& Business Media. [12] Khan, W. A., Culham, J. R., and Yovanovich, M. M., 2006, "Convection heat transfer from tube banks in crossflow: Analytical approach," International Journal of Heat and Mass Transfer, 49(25), pp. 4831-4838.

[13] Owen, J., and Roger, R., 1989, "Flow and heat transfer in rotating-disc systems. Volume I-Rotor-stator systems," NASA STI/Recon Technical Report A, 90.

[14] Tian, X., and Kennedy, J. F. E., 1994, "Maximum and Average Flash Temperatures in Sliding Contacts," Journal of Tribology, 116(1), pp. 167-174.

[15] Archard, J., 1959, "The temperature of rubbing surfaces," wear, 2(6), pp. 438-455.

[16] Yovanovich, M. M., 2005, "Four decades of research on thermal contact, gap, and joint resistance in microelectronics," IEEE transactions on components and packaging technologies, 28(2), pp. 182-206.

[17] Machado, H. A., 2014, "Modeling heat transfer with micro-scale natural convection in fibrous insulation," Journal of the Brazilian Society of Mechanical Sciences and Engineering, 36(4), pp. 847-857.

[18] Hu, X. J., Jain, A., and Goodson, K. E., 2008,

"Investigation of the natural convection boundary condition in microfabricated structures," International Journal of Thermal Sciences, 47(7), pp. 820-824.

[19] Lelli, D., Chew, J. W., and Cooper, P., 2005, "Combined 3D Fluid Dynamics and Mechanical Modelling of Brush Seals," (47268), pp. 1207-1216.

[20] Logg, A., Mardal, K.-A., and Wells, G., 2012, Automated solution of differential equations by the finite element method: The FEniCS book, Springer Science \& Business Media.

[21] Yevtushenko, A., Ukhanska, O., and Chapovska, R., 1996, "Friction heat distribution between a stationary pin and a rotating disc," Wear, 196(1), pp. 219-225. 
